\title{
NEW EVIDENCE ON BETA STATIONARITY AND FORECAST FOR BELGIAN COMMON STOCKS
}

\author{
Hawawini Gabriel A ${ }^{(1)}$ Michel Pierre ${ }^{(2)}$ Corhay Albert ${ }^{(2)}$ \\ (1) European Institute of Business Administration (INSEAD), 77305 Fontainebleau, France \\ ${ }^{(2)}$ University of Liège, 4000 Liège, Belgium
}

\begin{abstract}
Based on a comprehensive sample of 170 securities traded continuously on the Brussels Stock Exchange from December 1966 to December 1983 this paper presents evidence which indicates that the stationarity of beta-coefficients is not as strong as reported in previous studies which were based on smaller samples. It is shown, however, that beta forecast can be generally improved using an adjustment method and that the improvement is highest for portfolios of increasing size.
\end{abstract}

\section{Introduction}

The systematic risk of a security known as its beta coefficient is a central concept in capital market theory. Practical applications of this theory require that historical betas be estimated with the least amount of measurement errors and that their future values be predicted as accurately as possible. It is the stationarity and forecast aspects of beta coefficient that are the concern of this paper.

The simplest forecast of next period beta is the most recent historical estimate of beta. The purpose of this paper is to find out if the accuracy of the forecast of next period beta, for a comprehensive sample of Belgian common stocks, can be improved by adjusting the historical estimates of beta according to three alternative adjustment techniques: the Bayesian method developed by Vasicek (1973), the method developed by Blume $(1971,1975)$ and that used by the brokerage firm of Merrill, Lynch, Pierce, Fenner and Smith (MLPFS). These adjustment techniques are described in the third section.

The next section combines a brief summary of previous work and a presentation of the properties of the sample used in this study. Methodological issues are discussed in section 3. Section 4 presents the empirical findings. Our major result is that the stationarity of beta coefficients for Belgian common stocks is not as strong as previous studies have shown. Their forecast, however, can be generally improved using an adjustment method and the improvement is highest for portfolios of increasing size. The last section contains concluding remarks.

\section{Previous work and sample properties}

Klemkosky and Martin (1975) have examined the question of adjusting beta forecasts for a sample of U.S. common stocks and concluded that 'the accuracy of a simple no-change extrapolative beta forecast can be improved. A combination of the Bayesian (Vasicek) predictor and a reasonable portfolio size would appear to make the beta coefficient a highly predictable risk surrogate.'

Recently, Eubank and Zumwalt (1979) confirmed Klemkosky and Martin's results over estimation periods of 12 to 120 months.

To our knowledge, apart from the case of U.K. stocks [Dimson and Marsh (1983)], there is no published account of an evaluation of the adjustment of beta forecasts for European common stocks. This study will focus on stocks traded on the Brussels Stock Exchange (BSE). The stationar-ity of Belgian betas was investigated by Hawawini and Michel $(1978,1979)$, and by Fabry and Van Grembergen (1978). The former have concluded that Belgian betas are generally more stationary than French or U.S. betas but they did not examine if a simple no-change extrapolative beta forecast can be improved. The latter concluded that the true betas of small portfolios — as opposed to the estimated 
betas - are generally stationary. Single security betas, however, were not found to be stationary. Again, no attempt is made to see if adjusting the estimated betas will improve their accuracy in predicting the next period betas.

Another important aspect of this paper which differentiates it from previous work on Belgian stocks is the property of the sample used. Hawawini and Michel $(1978,1979)$ had a sample of only 30 common stocks and Fabry and Van Grembergen (1978) had a sample of 46 stocks. These were small samples that contained the most frequently traded securities with the largest market values of shares outstanding. The sample used in this study contains 170 securities. It consists of all the securities which were listed continuously on the BSE over the 17-year period starting in December 1966 and ending in December 1983. Empirical results drawn from this comprehensive sample show that beta stationarity is not as strong as reported by either Hawawini and Michel or Fabry and Van Grembergen. It is possible that the relatively stronger stationarity observed by these authors was due to the fact that they restricted their investigations to a sample of securities which were frequently traded and had large market values.

\section{Methodology}

\subsection{Adjustment methods}

A security's beta coefficient can be estimated from historical price data using the well-known market model [Sharpe (1963), Fama (1973)]:

$$
\tilde{R}_{i, t}=\alpha_{i}+\beta_{i} \tilde{R}_{m, t}+\tilde{\varepsilon}_{i, t}
$$

where $\widetilde{R}_{i, t}$ is the monthly total return of security $i, \widetilde{R}_{m, t}$ is the corresponding

rate of return of a market index which we take as the arithmetic average of the 170 securities in our sample and $\tilde{t}_{i, \mathrm{e}}$ is a random variable assumed to be serially uncorrected with zero expected value and constant variance.

Consider the following notations:

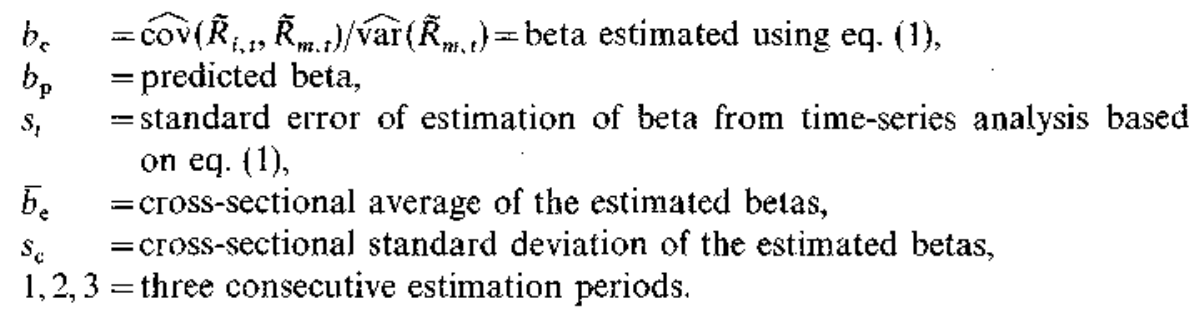

If the beta forecasts are not adjusted, then next period betas are predicted by betas estimated over the preceding period. We have

$$
b_{2 \mathrm{p}}=b_{1 \mathrm{e}}
$$

That is, our forecast of period-two beta $\left(\mathrm{b}_{2} \mathrm{p}\right)$ is beta estimated over period one $\left(b_{1}\right)$. This is the simple no-change extrapolative beta forecast.

Alternative forecast of period-two beta, however, can be obtained by adjusting the simple no-change extrapolative forecast $\left(b_{1 e}\right)$ by one of three methods. The first is the Bayes-Vasicek adjustment which is given by

$$
b_{2 p}^{\prime}=\frac{\left(b_{1 \mathrm{c}} / s_{1 t}^{2}\right)+\left(\bar{b}_{1 \mathrm{c}} / s_{1 \mathrm{c}}^{2}\right)}{\left(1 / s_{1 \mathrm{j}}^{2}\right)+\left(1 / s_{1 \mathrm{c}}^{2}\right)} .
$$


This estimator uses information on the standard error of estimation of beta $\left(s_{1 t}\right)$, the cross-sectional average of the estimated betas $\left(\bar{b}_{1}\right)$ and the cross-

sectional standard deviation of the estimated betas (s1c) to adjust the no-change extrapolative forecast $\left(b_{l}\right.$ e) estimated using (1).

The second estimator is given by the Blume adjustment method. We have

$$
b_{3 p}^{\prime \prime}=\hat{i}+\hat{\gamma} b_{2 e}
$$

where $\hat{\partial}$ and $\hat{\gamma}$ are estimated using the regression $b_{2 e}=S+\gamma b_{1 e}$ and error. Note that the derivation of the Blume estimator requires two consecutive periods (period one and period two) preceding the forecast period (period three) in order to estimate the coefficient $\partial$ and $\gamma$.

The third and last alternative estimator is the MLPFS estimator given by

$$
b_{3 \mathrm{p}}^{\prime \prime \prime}=1+\rho\left(b_{2 \mathrm{e}}-1\right)
$$

where $\rho$ is the product moment correlation between $b_{1 \mathrm{e}}$ and $b_{2 \mathrm{e}}$. Again, as in the case of the Blume estimator, two consecutive periods preceding the forecast period are required in order to estimate $\rho$.

\subsection{Evaluation techniques}

We wish to evaluate the predictive ability of the four alternative beta forecasts $\left(b_{p}, b_{p}^{\prime}, b_{p}^{\prime \prime}\right.$, and $\left.b_{p}{ }^{\prime \prime \prime}\right)$ of next period beta. To do so, we can first estimate the value of beta which has actually occurred over the next period and then compare this realized value of beta $\left(b_{r}\right)$ with each one of the four alternative forecasts.

The predictive ability of each one of the four alternative beta forecasts can be measured by the product moment correlation coefficient between each predicted value and the realized value of beta. The higher the correlation the more accurate is the forecast. This method suffers from known deficiencies.

An alternative and more general method of evaluating the predictive ability of beta forecasts is to compute the mean square forecasting error $(M S E)$ between predicted $\left(b_{p}\right)$ and realized $\left(b_{r}\right)$ beta coefficients and to examine its components [Mincer and Zarnowitz (1969)]. We have

$$
\begin{aligned}
& M S E=\frac{1}{N} \sum_{i=1}^{n}\left(b_{\mathrm{ri}}-b_{\mathrm{p} i}\right)^{2} \\
& M S E=\left(\bar{b}_{\mathrm{r}}-\vec{b}_{\mathrm{p}}\right)^{2}+\left(1-s_{\mathrm{rp}}\right)^{2}\left(s_{\mathrm{c}}^{2}\right)_{\mathrm{p}}+\left(1-k_{\mathrm{rp}}^{2}\right)\left(s_{\mathrm{c}}^{2}\right)_{\mathrm{r}}
\end{aligned}
$$

where $\mathrm{s}_{\mathrm{rp}}$ is the slope coefficient of the regression of $b_{r}$ on $\mathrm{b}_{\mathrm{p}},\left(\mathrm{s}_{\mathrm{c}}{ }^{2}\right)_{\mathrm{p}}$ and $\left(\mathrm{s}_{\mathrm{c}}{ }^{2}\right)_{\mathrm{r}}$ are the cross-sectional sample variances of $b_{p}$ and $b_{r}$, respectively; and $k_{r p}$ is the correlation coefficient between $\mathrm{b}_{\mathrm{r}}$ and $b_{p}$.

The first term in eq. (6) is the bias component which indicates the portion of the MSE due to over- or underestimation of the mean of realized betas $\left(\bar{b}_{\mathrm{r}}\right)$ over the mean of predicted betas $\left(\bar{b}_{\mathrm{r}}\right)$. The second term is the inefficiency component which captures the tendency of the forecast errors to be positive for low values of $b_{p}$ and negative for high values of $b_{p}$. The last term represents the random component of the MSE. Note that a perfect correlation between $b_{r}$ and $\mathrm{b}_{\mathrm{p}}\left(\mathrm{k}_{\mathrm{rp}}=\mathrm{l}\right)$ will reduce the random component to zero but will not produce a zero $M S E$. The $M S E$ will be zero only if the predicted values of betas $\left(b_{p}\right)$ are identical to their realized values $\left(b_{r}\right)$. 


\section{Empirical findings}

\subsection{Securities}

The sample consists of all the securities which traded continuously from December 1966 to December 1983 on the Brussels Stock Exchange. There were 170 securities meeting this criterion. The total 17year estimation period was divided into subperiods. The subperiods produced estimates of correlation coefficients and MSEs. These were then averaged over common sub-periods (either two or three) to yield a single value of the correlation coefficient and the $M S E$ for each type of forecasting method analyzed. The method was repeated for varying portfolio size. The monthly total returns on the market index were generated by assuming an equal investment in each one of the 170 securities in the sample.

Using the market model expressed in eq. (1) we first obtained estimates of each security's beta coefficient over two consecutive subperiods of equal length (90 months each). Betas estimated over the first subperiod were either unadjusted (these betas are referred to as 'classical' estimators) or adjusted according to the Bayes - Vasicek method. Average correlation coefficients and MSEs for predicted vs. realized betas are summarized in the upper part of table 1 .

The total 17-year estimation period was also broken down into three consecutive subperiods of equal length (36 months each). Classical and Bayes estimators were computed over the first and second subperiods and compared to realized betas over the subsequent subperiods. We also compared the classical and the Bayes estimators obtained over the first subperiod to the realized betas over the third subperiod. Finally, using the first two subperiods we calculated the MLPFS and the Blume estimators which we compared to realized betas over the third subperiod. All the results are summarized in table 1. The following observations can be made:

(1) The correlation coefficients are weaker than those reported by either Hawawini and Michel $(1978,1979)$, or Fabry and Van Grembergen(1978). ${ }^{1}$

Thus, earlier evidence of stronger stationarity may be due to the small and biased sample used by these authors.

(2) The value of the correlation for the Bayes-adjusted forecasts is higher than that of the unadjusted (classical) forecast. The Blume-adjusted betas and the MLPFS-adjusted betas do not yield higher correlations than unadjusted betas.

(3) MSEs can be significantly reduced by adjusting beta forecasts. The reduction in the MSEs comes primarily from the inefficiency component of total $M S E$. Referring to the lower part of table 1, we can see that no particular adjustment technique provides a better reduction of MSE. The total MSE of adjusted betas is, for all three techniques, about $30 \%$ smaller than that of the unadjusted beta.

The latter report a correlation coefficient of 0.402 based on monthly returns for individual securities over a total estimation period starting in 1964 and ending in 1975. This total period was broken down into 2 subperiods of equal length (see their table 1). 
Table 1 Average correlation coefficients and mean square errors for 170 securities (December 1966 to December 1983).

\begin{tabular}{|c|c|c|c|c|c|c|}
\hline $\begin{array}{l}\text { Forecasting } \\
\text { method }\end{array}$ & $\begin{array}{l}\text { Correlation } \\
\text { coefficient }\end{array}$ & L Bias & Inefficiency & $\begin{array}{c}\text { Random } \\
\text { error }\end{array}$ & $\begin{array}{l}\text { Total } \\
\text { MSE }\end{array}$ & 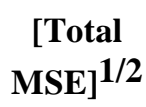 \\
\hline \multicolumn{7}{|c|}{2 periods (68 months each) } \\
\hline Classical $^{b}$ & $0.21507^{\mathrm{a}}$ & 0.00000 & 0.20183 & 0.20619 & 0.40802 & 0.63876 \\
\hline Bayes ${ }^{b}$ & $0.23543^{\mathrm{a}}$ & 0.00133 & 0.09270 & 0.20416 & 0.29819 & 0.54607 \\
\hline \multicolumn{7}{|c|}{3 periods (36 months each) } \\
\hline Classical $^{\mathrm{c}}$ & $0.29195^{\mathrm{a}}$ & 0.00000 & 0.12550 & 0.29501 & 0.42051 & 0.64847 \\
\hline Bayes ${ }^{c}$ & $0.31069^{\mathrm{a}}$ & 0.00074 & 0.02942 & 0.29213 & 0.32229 & 0.56771 \\
\hline Classical $^{\mathrm{d}}$ & $0.20741^{\mathrm{a}}$ & 0.00000 & 0.16577 & 0.33991 & 0.50568 & 0.71111 \\
\hline Bayes $d$ & $0.20666^{\mathrm{a}}$ & 0.00074 & 0.04979 & 0.34178 & 0.39231 & 0.62635 \\
\hline Classical $^{\mathrm{e}}$ & $0.32893^{\mathrm{a}}$ & 0.00000 & 0.14615 & 0.31623 & 0.46238 & 0.68000 \\
\hline Bayes ${ }^{\mathrm{e}}$ & $0.33945^{\mathrm{a}}$ & 0.00077 & 0.02951 & 0.31375 & 0.34403 & 0.58654 \\
\hline MLPFS $\mathrm{e}^{\mathrm{e}}$ & $0.32893^{\mathrm{a}}$ & 0.00000 & 0.01125 & 0.31623 & 0.32748 & 0.57226 \\
\hline Blume ${ }^{\mathrm{e}}$ & $0.32893^{\mathrm{a}}$ & 0.00000 & 0.01153 & 0.31623 & 0.32776 & 0.57250 \\
\hline \multicolumn{7}{|c|}{ ignificant correlation at the $5 \%$ level. } \\
\hline $\begin{array}{l}\text { erage over: }(1-1- \\
\text { erage over: }(1-\mathrm{C}\end{array}$ & $-72)$ and $(9-72$ & $(9-7$ & $n d(5-78 / 1$ & 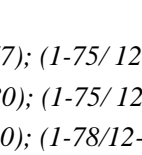 & . & $\begin{array}{l}\text { 2-80). } \\
\text { 2-83). }\end{array}$ \\
\hline
\end{tabular}

Table 2 Average correlation coefficients and mean square errors for portfolios [3 periods (36 months each)]. ${ }^{a}$

$\begin{array}{cccccccc}\begin{array}{c}\text { Portfolio } \\ \text { size }\end{array} & \begin{array}{c}\text { Forecasting } \\ \text { method }\end{array} & \begin{array}{c}\text { Correlatio } \\ \mathbf{n} \\ \text { coefficient }\end{array} & \begin{array}{c}\text { l } \\ \text { Bias }\end{array} & \begin{array}{c}\text { Inefficien } \\ \text { cy }\end{array} & \begin{array}{c}\text { Random } \\ \text { error }\end{array} & \begin{array}{c}\text { Total } \\ \boldsymbol{M S E} \boldsymbol{E}\end{array} & \begin{array}{c}{[\text { Total }} \\ \boldsymbol{M S E}]^{\mathbf{1} / 2}\end{array} \\ & \text { Classical } & 0.40055^{\mathrm{b}} & 0.00000 & 0.06219 & 0.16066 & 0.22285 & 0.47207 \\ & \text { Bayes } & 0.40758^{\mathrm{b}} & 0.00029 & 0.01455 & 0.15990 & 0.17474 & 0.41802 \\ & \text { MLPFS } & 0.40055^{\mathrm{b}} & 0.00000 & 0.01316 & 0.16066 & 0.17382 & 0.41692 \\ 5 & \text { Blume } & 0.40055^{\mathrm{b}} & 0.00000 & 0.01218 & 0.16066 & 0.17284 & 0.41574 \\ & \text { Classical } & 0.47572^{\mathrm{b}} & 0.00000 & 0.03227 & 0.06828 & 0.10055 & 0.31710 \\ & \text { Bayes } & 0.47047^{\mathrm{b}} & 0.00008 & 0.01100 & 0.06887 & 0.07995 & 0.28275 \\ & \text { MLPFS } & 0.47572^{\mathrm{b}} & 0.00000 & 0.01265 & 0.06828 & 0.08093 & 0.28448 \\ & \text { Blume } & 0.47572^{\mathrm{b}} & 0.03591 & 0.01575 & 0.06828 & 0.11994 & 0.34632 \\ & \text { Classical } & 0.57337^{\mathrm{b}} & 0.00000 & 0.02107 & 0.03457 & 0.05564 & 0.23588 \\ & \text { Bayes } & 0.56762^{\mathrm{b}} & 0.00004 & 0.01027 & 0.03529 & 0.04560 & 0.21354 \\ & \text { MLPFS } & 0.57337^{\mathrm{b}} & 0.00000 & 0.01130 & 0.03457 & 0.04587 & 0.21417 \\ & \text { Blume } & 0.57337^{\mathrm{b}} & 0.02474 & 0.01177 & 0.03457 & 0.07108 & 0.26661 \\ & \text { Classical } & 0.71506^{\mathrm{b}} & 0.00000 & 0.01285 & 0.01704 & 0.02989 & 0.17289 \\ & \text { Bayes } & 0.72225^{\mathrm{b}} & 0.00002 & 0.00691 & 0.01684 & 0.02377 & 0.15417 \\ & \text { MLPFS } & 0.71506^{\mathrm{b}} & 0.00000 & 0.01248 & 0.01704 & 0.02952 & 0.17181\end{array}$

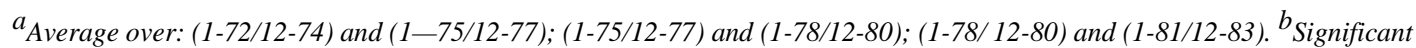
correlation at the $5 \%$ level. 


\subsection{Portfolios}

Correlation coefficients and MSEs were also obtained for portfolios of varying size. These portfolios were constructed by ranking individual securities' betas in decreasing order of value and assigning the first n-securities to the first portfolio of size $n$ and so on until every security in the sample had been assigned to a portfolio. Empirical results are summarized in table 2. We observe the following:

(1) As portfolio size increases, the correlation coefficients rise and total MSEs fall. This is consistent with what has been observed on the New York Stock Exchange.

(2) Most of the reduction in the MSEs comes from the random error component of total MSEs.

(3) Bayes-adjusted betas tend to provide the best forecast. With a portfolio size of 17 securities, the total MSE of the Bayes-adjusted beta is reduced to $89 \%$ of the value of the total MSE of unadjusted betas.

\section{Conclusion}

In this paper, we presented evidence that the stationarity of beta coefficients for Belgian common stocks is not as strong as previous studies have shown. Their forecast, however, can be generally improved using an adjustment method. We have shown that over a 17 -year sample period the forecast error of adjusted betas is about $30 \%$ smaller than the forecast error of a simple no-change extrapolative beta forecast for individual securities. The forecast error can be further reduced if one uses portfolios of securities.

\section{Notes}

${ }^{1}$ We should point out that our estimation periods do not exactly correspond to those used by Hawawini and Michel (1978, 1979), or Fabry and Van Grembergen (1978). The former report a correlation coefficient of 0.699 based on monthly returns for individual securities over a total estimation period starting in 1963 and ending in 1976. The total period was broken down into 2 subperiods of equal length (see their table 1).

\section{References}

Blume, M., 1971, On the assessment of risk, Journal of Finance, March, 1-10.

Blume, M., 1975, Betas and their regression tendencies, Journal of Finance, June, 785-795.

Dimson, E. and P. Marsh, 1983, The stability of UK risk measures and the problem of thin trading, Journal of Finance, June, 753-783.

Eubank, A. and J. Zumwalt, 1979, An analysis of the forecast error impact of alternative beta adjustment techniques and risk classes, Journal of Finance, June, 761-776.

Fabry, J. and W. Van Grembergen, 1978, Further evidence on the stationarity of betas and errors in their estimates, Journal of Banking and Finance, Sept., 189-204.

Fama, E., 1973, A note on the market model and the two-parameter model, Journal of Finance, Dec, 1181-1185.

Hawawini, G. and P. Michel, 1978, Modele de marche et evaluation du risque sur la Bourse de Bruxelles, Analyse Financiere, March, 67-76.

Hawawini, G. and P. Michel, 1979, An assessment of risk in thinner markets: The Belgian case, Journal of Economics and Business, Spring/Summer, 196-201. 
Published in : Journal of banking and finance (1985) vol. 9, iss. 4, pp. 553-560

Status : Postprint (Author's version)

Klemkosky, R. and J. Martin, 1975, The adjustment of beta forecasts, Journal of Finance, Sept., 11231128.

Mincer, J. and V. Zarnowitz, 1969, The evaluation of economic forecasts, in: J. Mincer, ed.,Economic forecasts and expectations (Columbia University Press, New York) 6-14.

Sharpe, W., 1963, A simplified model for portfolio analysis, Management Science, Jan., 277-293.

Vasicek, O., 1973, A note on using cross-sectional information in Bayesian estimation of security betas, Journal of Finance, Dec, 1233-1239. 